\title{
A decision impact, decision conflict and economic assessment of routine Oncotype DX testing of 146 women with node-negative or pNImi, ER-positive breast cancer in the UK
}

S Holt ${ }^{*}, 1$, G Bertelli ${ }^{2}$, I Humphreys ${ }^{3}$, W Valentine ${ }^{4}$, S Durrani ${ }^{5}$, D Pudney ${ }^{2}$, M Rolles $^{2}$, M Moe $^{2}$, S Khawaja ${ }^{1}$, Y Sharaiha ${ }^{1}$, E Brinkworth ${ }^{2}$, S Whelan ${ }^{2}$, S Jones ${ }^{5}, \mathrm{H}_{\text {Bennett }}{ }^{3}$ and C J Phillips ${ }^{3}$

${ }^{1}$ Department of Breast Surgery, Prince Philip Hospital, Llanelli, Wales SA14 8QF, UK; ${ }^{2}$ Department of Oncology, Singleton Hospital, Swansea, Wales SA2 8QA, UK; ${ }^{3}$ Swansea Centre for Health Economics, Swansea University, Swansea, Wales SA2 8PP, UK; ${ }^{4}$ Ossian Health Economics and Communications, Bauleingasse, 4051 Basel, Switzerland and ${ }^{5}$ Department of Oncology, Bronglais Hospital, Aberystwyth, Wales SY23 1ER, UK

Background: Tumour gene expression analysis is useful in predicting adjuvant chemotherapy benefit in early breast cancer patients. This study aims to examine the implications of routine Oncotype DX testing in the UK.

Methods: Women with oestrogen receptor positive $(E R+), p N O$ or $\mathrm{pN} 1 \mathrm{mi}$ breast cancer were assessed for adjuvant chemotherapy and subsequently offered Oncotype DX testing, with changes in chemotherapy decisions recorded. A subset of patients completed questionnaires about their uncertainties regarding chemotherapy decisions pre- and post-testing. All patients were asked to complete a diary of medical interactions over the next 6 months, from which economic data were extracted to model the cost-effectiveness of testing.

Results: Oncotype DX testing resulted in changes in chemotherapy decisions in 38 of 142 (26.8\%) women, with 26 of 57 (45.6\%) spared chemotherapy and 12 of $85(14.1 \%)$ requiring chemotherapy when not initially recommended ( $9.9 \%$ reduction overall). Decision conflict analysis showed that Oncotype DX testing increased patients' confidence in treatment decision making. Economic analysis showed that routine Oncotype DX testing costs £6232 per quality-adjusted life year gained.

Conclusion: Oncotype DX decreased chemotherapy use and increased confidence in treatment decision making in patients with ER + early-stage breast cancer. Based on these findings, Oncotype DX is cost-effective in the UK setting.

The Oncotype DX 21-gene assay is validated to predict benefit from chemotherapy in women with early breast cancer (Paik et al, 2006; Albain et al, 2010). It is included in the American Society of Clinical Oncology (Harris et al, 2007) and National Comprehensive Cancer Network (NCCN Clinical Practice Guidelines in Oncology Breast Cancer, 2011), ESMO (Aebi et al, 2010) and St Gallen guidelines (Goldhirsch et al, 2011) as an adjunct to decision making for oncologists when considering the appropriateness of chemotherapy.
This study looks at the impact if this test were to be adopted for all node negative or micrometastatic, oestrogen receptor (ER)positive women fit for chemotherapy in the setting of the UK National Health Service. We looked at the effect on chemotherapy prescribing (decision impact), the acceptability to patients of applying this test (decision conflict analysis) and assessed the cost-effectiveness in terms of cost per quality-adjusted life year (QALY).

*Correspondence: S Holt; E-mail: simon_holt@mac.com

Received 12 November 2012; revised 11 March 2013; accepted 1 April 2013;

published online 21 May 2013

(c) 2013 Cancer Research UK. All rights reserved 0007-0920/13

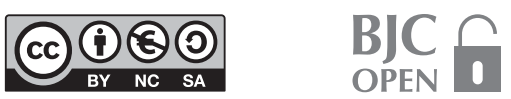




\section{MATERIALS AND METHODS}

A total of 150 tests were available to five oncologists working in one cancer centre in West Wales. Women with excised ER-positive (Allred score $\geqslant 3 / 8$ by immunohistochemistry IHC) and nodenegative $(\mathrm{pN} 0, \mathrm{pN} 0 \mathrm{i}+$ ) invasive breast cancer or with minimal node involvement ( $\mathrm{pN} 1 \mathrm{mi}$ ) were identified at the multidisciplinary team meetings as being suitable for testing and oncologists were encouraged to include them even if initial assessment suggested they were at very low risk of recurrence, so as to best reflect testing of this whole cohort. At their initial consultation with their oncologist, patients were assessed for fitness to receive chemotherapy, if recommended. Women under 18 years, pregnant, unable to comprehend the details of the trial, unable to complete the documentation in English or who had a previous history of breast cancer treatment were excluded. Participants were asked to provide signed informed consent before inclusion in the trial. The Hywel Dda Health Board Research and Development Committee and Dyfed Powys Ethics Committee approved the study.

Decision impact study method. Once the full post surgical histopathology results were available, each patient was seen by her oncologist to discuss adjuvant therapy. With this information (size, grade, type, ER, progesterone receptor (PR), HER2 and node status) and with added information from Adjuvant! online, the oncologist discussed chemotherapy with the patient. A written recommendation for or against chemotherapy was made at the conclusion of the consultation taking into account both the patient's and the oncologist's views. The Oncotype DX test was requested and a second meeting between the patient and her oncologist was scheduled once the result was available. The Recurrence Score result was reviewed and this information was added to the clinical data already available and a final decision for or against chemotherapy recorded.

Decision conflict study methods. During the latter half of the study, patients seen at one institution were asked to complete a 16-item decision conflict questionnaire immediately following their pre- and post-Oncotype DX consultation. The Decision Conflict Scale (DCS) was based on a 16-item questionnaire. Each item was scored as: $1=$ 'strongly agree', $2=$ 'agree', $3=$ 'neither agree nor disagree', $4=$ 'disagree' and $5=$ 'strongly disagree'. The total score was based on all 16 items. There were five subscores (informed, values clarity, support, uncertainty and effective decision). The User Manual for the DCS specifies that each subscore and the total score should be calculated by averaging the responses to the relevant items, and scaling each score $0-100$. Smaller scores reflect less decisional conflict. The following method was used for this analysis:

- A subscore was calculated only if there were responses to at least two items.

- If any subscore was missing, then no total score was calculated.

From the total and the five subscores, the means and the mean changes were calculated for each questionnaire. A paired $t$-test was used to assess the significance of any change between pre- and post-testing scores.

Cost-effectiveness method. The analysis was performed using a Markov model (based on a previously published model by Hornberger et al, 2005) consisting of three states with a cycle length of 1 year (incorporating half-cycle correction). All patients begin the model in the recurrence-free state, and may transition to recurrence (following a distant recurrence event) or death (following a mortality event).

The analysis compared two approaches to inform treatment recommendations for adjuvant therapy: (1) Conventional diagnostic procedures (including Adjuvant! Online and the Nottingham Prognostic Index) and (2) the Oncotype DX assay. In the Oncotype DX arm, treatment recommendations were then reviewed following availability of the Recurrence Score result (Holt et al, 2011).

In each cycle of the simulation, patients were exposed to the competing risks of mortality and recurrence. Clinical input data were derived from landmark Oncotype DX studies for the risk of recurrence, and mortality rates were taken from UK-specific life tables.

In each cycle of the model, recurrence risk for each simulated patient is evaluated based on the Recurrence Score category (low, intermediate or high, as reported by Paik et al, 2006; Figure 1). Risk was then adjusted based on whether patients were receiving

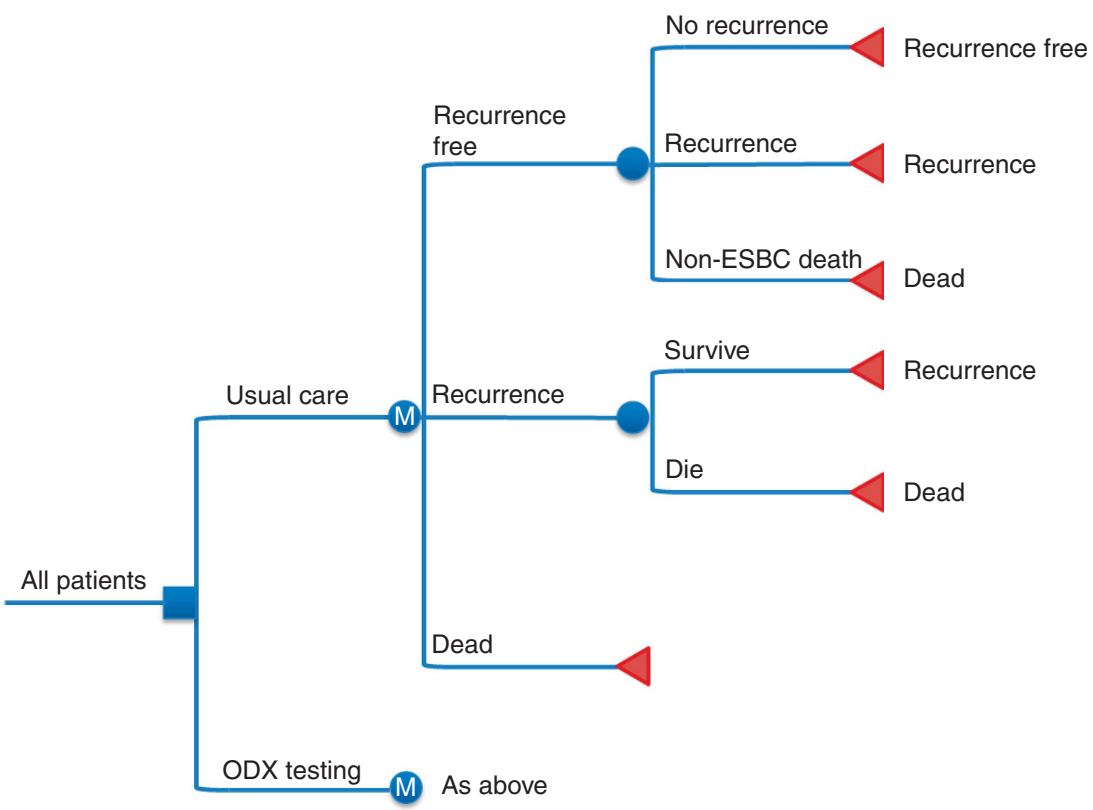

Figure 1. Structure of the cost-effectiveness model. 
chemotherapy as per initial recommendations (in the usual care arm) and based on the Recurrence Score result (in the Oncotype DX arm). A summary of clinical variables used in the model is shown in Table 1.

Costs, utilities, discounting and time horizon. All patients were asked to complete a diary of medical interactions over the 6 months following inclusion in the study. Hospital notes and electronic chemotherapy prescription records were also used to estimate the total cost of chemotherapy for the costeffectiveness analyses. All other treatment costs used in the model were derived from UK-specific sources and were inflated, where necessary, to 2010 GBP using the Hospital and Community Health Services pay and price inflation index. Unit costs used in the model are summarised in Table 2. The utility scores used in the model were derived from published literature. Mean (s.e.) utility scores used in the model for the recurrencefree state, recurrence state and chemotherapy treatment (6 cycles) were $0.78(0.03), 0.60(0.03)$ and $-0.07(0.01)$, respectively (Conner-Spady et al, 2005; Milne et al, 2006; Peasgood et al, 2010).

Adverse event rates for the first 5 years of endocrine therapy were also accounted in the model based on published data (Hind et al, 2007). In relation to adverse events, the following assumptions were made:
- $40 \%$ patients with vaginal bleeding received an ultrasound scan, $40 \%$ received a hysterectomy and $20 \%$ received both

- Patients with endometrial cancer received the same diagnostics and treatment costs as for vaginal bleeding, plus all patients received a hysterectomy and $50 \%$ received radiotherapy

- $0.4 \%$ patients with deep vein thrombosis developed pulmonary embolism

- $80 \%$ of ischemic cerebrovascular events were assumed to be strokes, the remaining $20 \%$ were assumed to be transient ischemic attacks and only first year costs were included for both stroke and transient ischemic attack

The analysis was performed over a time horizon of 30 years and future costs and clinical outcomes were discounted at a rate of $3.5 \%$ per annum in line with current UK recommendations.

Sensitivity analyses. A series of one-way sensitivity analyses were performed to establish key drivers of outcomes. Most clinical and cost parameter inputs in the model were varied by $\pm 25 \%$ (with the exception of discount rate and time horizon). Sensitivity analyses were performed using a discount rate of 0 and $6 \%$ per annum for both future costs and clinical outcomes. Other one-way sensitivity analyses performed included changing the time horizon to 10,20 and 40 years (in comparison with 30 years in the base case), assuming that the cost of chemotherapy was based on five cycles

Table 1. Summary of clinical variables used in the cost-effectiveness model

\begin{tabular}{|c|c|c|c|c|}
\hline Variable & Mean & $\begin{array}{l}\text { s.e. (minimum, } \\
\text { maximum) }\end{array}$ & Distribution & Reference \\
\hline Age (years) & 60.55 & $6.06(17,100)$ & Normal & $\begin{array}{l}\text { Welsh Cancer Intelligence and Surveillance } \\
\text { Unit, Office of National Statistics and the } \\
\text { Scottish Cancer Registry }\end{array}$ \\
\hline $\begin{array}{l}\text { Net change in chemotherapy use with } \\
\text { low RS (\%) }\end{array}$ & -20.95 & $2.10(-31.43,10.48)$ & Normal & Holt et al, 2011 \\
\hline $\begin{array}{l}\text { Net change in chemotherapy use with } \\
\text { intermediate RS (\%) }\end{array}$ & 1.90 & $0.19(0.95,2.86)$ & Normal & Holt et al, 2011 \\
\hline $\begin{array}{l}\text { Net change in chemotherapy use with } \\
\text { high RS (\%) }\end{array}$ & 4.76 & $0.48(2.38,7.14)$ & Normal & Holt et al, 2011 \\
\hline $\begin{array}{l}\text { 10-Year risk of recurrence (low RS) on } \\
\text { endocrine therapy (\%) }\end{array}$ & 3.20 & $1.60(1.60,4.80)$ & Normal & Paik et al, 2006 \\
\hline $\begin{array}{l}\text { 10-Year risk of recurrence (intermediate RS) } \\
\text { on endocrine therapy (\%) }\end{array}$ & 9.10 & $4.30(4.55,13.65)$ & Normal & Paik et al, 2006 \\
\hline $\begin{array}{l}\text { 10-Year risk of recurrence (high RS) on } \\
\text { endocrine therapy (\%) }\end{array}$ & 39.50 & $7.30(19.75,59.25)$ & Normal & Paik et al, 2006 \\
\hline RRR with chemotherapy (low RS; \%) & 0 & NA & NA & Assumed based on Paik et al, 2006 \\
\hline RRR for chemotherapy (intermediate RS; \%) & 39.0 & $4.43(19.5,58.5)$ & Normal & Paik et al, 2006 \\
\hline RRR for chemotherapy (high RS; \%) & 74.0 & $3.95(37.0,111.0)$ & Normal & Paik et al, 2006 \\
\hline Post-recurrence survival (years) & 3.3 & $0.330(1.65,4.95)$ & Normal & Thomas et al, 2009 \\
\hline Mortality rates & $\begin{array}{l}\text { Indexed by } \\
\text { age }\end{array}$ & NA & NA & Office for National Statistics (2010) \\
\hline Oncotype DX test & 2580.00 & NA & NA & Genomic Health Ltd. (2011 list price) \\
\hline Endocrine therapy (years 1-5) & 857.43 & 85.74 & Gamma & $\begin{array}{l}\text { NICE costing template } 112 . \\
\text { Updated with BNF } 61\end{array}$ \\
\hline Endocrine therapy (years 6-8) & 123.44 & 12.34 & Gamma & $\begin{array}{l}\text { NICE costing template } 112 . \\
\text { Updated with BNF } 61\end{array}$ \\
\hline Endocrine therapy adverse events (years 1-5) & 39.90 & 3.99 & Gamma & Hind et al, 2007 \\
\hline Endocrine therapy adverse events (years 6-8) & 2.21 & 0.22 & Gamma & Hind et al, 2007 \\
\hline Distant recurrence (monthly) & 915.95 & 91.60 & Gamma & Thomas et al, 2009 \\
\hline
\end{tabular}


Table 2. Summary of treatment/management costs for patients receiving chemotherapy and those not receiving chemotherapy

\begin{tabular}{|c|c|c|c|c|}
\hline Resource use & $\begin{array}{l}\text { Chemo mean (s.d.) } \\
\quad n=35\end{array}$ & $\begin{array}{l}\text { No chemo mean (s.d.) } \\
\qquad n=107\end{array}$ & $\begin{array}{c}\text { Effect size }(95 \% \mathrm{Cl} \text { of the } \\
\text { difference) }\end{array}$ & $\begin{array}{l}\boldsymbol{P} \text {-value } \\
(<0.05)\end{array}$ \\
\hline GP cost & 67 (94) & $68(107)$ & $-1(-41$ to 39$)$ & 0.95 \\
\hline GP home visit cost & $3(20)$ & 1 (12) & $2(-3$ to 8$)$ & 0.41 \\
\hline GP phone consultation cost & 1 (4) & $1(6)$ & $0(-2$ to 2$)$ & 0.86 \\
\hline GP nurse cost & $4(19)$ & $23(120)$ & $-1(-59$ to 22$)$ & 0.37 \\
\hline District nurse cost & $398(721)$ & $29(151)$ & 369 (223 to 515$)$ & 0.00 \\
\hline Hospital nurse cost & $53(200)$ & $15(68)$ & 37 ( -7 to 82$)$ & 0.10 \\
\hline Lymphoedema clinic cost & $16(52)$ & $38(117)$ & $-23(-63$ to 18$)$ & 0.27 \\
\hline Hospital doctor cost & $236(246)$ & $218(294)$ & $18(-91$ to 127$)$ & 0.74 \\
\hline Counselors cost & $0(0)$ & $11(85)$ & $-11(-40$ to 17$)$ & 0.44 \\
\hline Physiotherapist cost & $1(6)$ & $3(14)$ & $-2(-7$ to 3$)$ & 0.35 \\
\hline Plastic surgeon cost & $14(46)$ & $8(46)$ & $6(-11$ to 24$)$ & 0.49 \\
\hline Hospital stay cost & 596 (1689) & $90(482)$ & 506 (147 to 865$)$ & 0.01 \\
\hline Herceptin cost & 2241 (8509) & $0(0)$ & 2241 (627 to 3856 ) & 0.07 \\
\hline Consultant cost & $79(107)$ & 82 (95) & $-3(-41$ to 35$)$ & 0.87 \\
\hline CT SIM planning cost & $1312(1158)$ & $1212(1,065)$ & $100(-319$ to 519$)$ & 0.64 \\
\hline Radiotherapy cost & $6987(4171)$ & $6680(4,286)$ & $306(-1333$ to 1946$)$ & 0.71 \\
\hline Radiotherapy review cost & $138(89)$ & 135 (103) & $3(-36$ to 41$)$ & 0.90 \\
\hline Radiotherapy boosts cost & $1433(2299)$ & $768(1,799)$ & 666 ( -78 to 1409$)$ & 0.08 \\
\hline Mould room cost & $6(21)$ & $5(20)$ & $2(-6$ to 9$)$ & 0.70 \\
\hline FEC cost & $1119(892)$ & $0(0)$ & 1119 (950 to 1288$)$ & 0.00 \\
\hline TAC cost & 1465 (2116) & $0(0)$ & 1465 (1063 to 1866$)$ & 0.00 \\
\hline $\begin{array}{l}\text { Pre-chemo assessment } \\
\text { cost }\end{array}$ & $60(44)$ & $0(0)$ & $60(51$ to 68$)$ & 0.00 \\
\hline Pre-chemo bloods cost & $27(8)$ & $0(0)$ & 27 (25 to 28 ) & 0.00 \\
\hline $\begin{array}{l}\text { Oncologist appointment } \\
\text { cost }\end{array}$ & $157(150)$ & $0(0)$ & $157(129$ to 186$)$ & 0.00 \\
\hline MUGA cost & $4(16)$ & $0(0)$ & $4(1$ to 7$)$ & 0.01 \\
\hline $\mathrm{ECHO}$ cost & $9(28)$ & $0(0)$ & $9(4$ to 15$)$ & 0.00 \\
\hline CDU doctor cost & $46(84)$ & $0(0)$ & 46 (30 to 62$)$ & 0.00 \\
\hline CDU triage nurse cost & $42(71)$ & $0(0)$ & 42 (28 to 55$)$ & 0.00 \\
\hline Bone scan cost & $26(64)$ & $56(84)$ & $-30(-60$ to 1$)$ & 0.06 \\
\hline GCSF cost & $3510(8246)$ & $0(0)$ & 3510 (66 to 5075$)$ & 0.00 \\
\hline Total cost & $20418(13052)$ & 9568 (6087) & 10850 (7642 to14 058) & 0.00 \\
\hline
\end{tabular}

per regimen (versus six cycles in the base case), varying the disutility of chemotherapy to 0.037 (Conner-Spady et al, 2005) and 0.5 (Simes and Coates, 2001), and changing the utility value for the recurrence state to 0.51 (Milne et al, 2006). Other one-way sensitivity analyses were performed around the proportion of patients on chemotherapy receiving growth colony-stimulating factor prophylaxis, post-recurrence survival rates and 10-year recurrence risks.

To test the robustness of the model and assess measures of likely variance around outcomes reported in the base case, probabilistic sensitivity analysis (PSA) was performed. Here, sampling of recurrence risks and relative risk reductions was performed from normal distributions, with variance defined based on published data (Table 1); for the PSA, a total of 1000 iterations were run.

\section{RESULTS}

Of the 146 patients enrolled, 4 were excluded: 1 patient withdrew from the trial before the result was available and the tissue samples for 3 patients did not meet pathology review criteria for the assay. Of the 142 patients who were evaluable for the final analysis, 2 failed the first assay but yielded a reportable result on a second block, and 1 patient had bilateral breast cancer with both tumours giving the same score. The patient characteristics are summarised in Table 3. The median age was 55 years (range 34-72). The tumour was removed in 112 of the women by wide excision and 30 by mastectomy, 5 with immediate reconstruction.

Patients receiving chemotherapy had significantly higher total mean (s.d.) treatment and management costs in comparison with 
RS

\section{Low $(<18) \quad$ Intermediate (18-30) $\quad$ High ( $\geqslant 31)$}

\begin{tabular}{|c|c|c|c|c|c|c|c|c|c|}
\hline & $n$ & $\%$ & $n$ & $\%$ & $n$ & $\%$ & $n$ & $\%$ & $P$-value \\
\hline All patients & 142 & 100.0 & 79 & 55.6 & 39 & 27.5 & 24 & 16.9 & \\
\hline Age $<55$ years & 67 & 47.2 & 38 & 56.7 & 18 & 26.9 & 11 & 16.4 & 0.809 \\
\hline Age $\geqslant 55$ years & 75 & 52.8 & 41 & 54.7 & 21 & 28.0 & 13 & 17.3 & \\
\hline pT1 & 92 & 64.8 & 49 & 53.3 & 29 & 31.5 & 14 & 15.2 & 0.703 \\
\hline pT2-3 & 50 & 35.2 & 30 & 60.0 & 10 & 20.0 & 10 & 20.0 & \\
\hline Grade 1 & 26 & 18.3 & 23 & 88.5 & 3 & 11.5 & 0 & 0.0 & $<0.001$ \\
\hline Grade 2 & 93 & 65.5 & 54 & 58.1 & 31 & 33.3 & 8 & 8.6 & \\
\hline Grade 3 & 23 & 16.2 & 2 & 8.7 & 5 & 21.7 & 16 & 69.6 & \\
\hline Ductal & 123 & 86.6 & 66 & 53.7 & 34 & 27.6 & 23 & 18.7 & 0.154 \\
\hline Non-ductal & 19 & 13.4 & 13 & 68.4 & 5 & 26.3 & 1 & 5.3 & \\
\hline ER 7-8 & 134 & 94.4 & 78 & 58.2 & 37 & 27.6 & 19 & 14.2 & 0.002 \\
\hline ER 3-6 & 8 & 5.6 & 1 & 12.5 & 2 & 25.0 & 5 & 62.5 & \\
\hline PgR 7-8 & 82 & 59.0 & 57 & 69.5 & 19 & 23.2 & 6 & 7.3 & $<0.001$ \\
\hline PgR 5-6 & 23 & 16.2 & 12 & 52.2 & 7 & 30.4 & 4 & 17.4 & \\
\hline PgR 3-4 & 19 & 13.4 & 6 & 31.6 & 7 & 36.8 & 6 & 31.6 & \\
\hline PgR neg & 15 & 10.6 & 1 & 6.7 & 6 & 40.0 & 8 & 53.3 & \\
\hline HER2 0 & 37 & 26.1 & 19 & 51.4 & 13 & 35.1 & 5 & 13.5 & 0.118 \\
\hline HER2 $1+$ & 72 & 50.7 & 46 & 63.9 & 18 & 25.0 & 8 & 11.1 & \\
\hline HER2 $2+$ & 22 & 15.5 & 9 & 40.9 & 6 & 27.3 & 7 & 31.8 & \\
\hline HER2 $3+$ & 4 & 2.8 & 0 & 0.0 & 1 & 25.0 & 3 & 75.0 & \\
\hline pNO & 121 & 85.2 & 66 & 54.5 & 34 & 28.1 & 21 & 17.4 & 0.545 \\
\hline $\mathrm{pNO}$ (itc +) & 10 & 7.0 & 6 & 60.0 & 3 & 30.0 & 1 & 10.0 & \\
\hline $\mathrm{pN1}$ (mic) & 11 & 7.7 & 7 & 63.6 & 2 & 18.2 & 2 & 18.2 & \\
\hline No risk factors & 19 & 13.4 & 19 & 100.0 & 0 & 0.0 & 0 & 0.0 & $<0.001$ \\
\hline 1 Risk factor & 70 & 49.3 & 45 & 64.3 & 20 & 28.6 & 5 & 7.1 & \\
\hline$\geqslant 2$ Risk factors & 53 & 37.3 & 15 & 28.3 & 19 & 35.8 & 19 & 35.8 & \\
\hline
\end{tabular}

Summary of chemotherapy changes by RS

\begin{tabular}{|c|c|c|c|c|c|c|c|c|c|}
\hline $\begin{array}{l}\text { Chemotherapy } \\
\text { recommended: before } \\
\text { Oncotype }\end{array}$ & 57 & 40.1 & 26 & 18.3 & 16 & 11.3 & 15 & 10.6 & \\
\hline $\begin{array}{l}\text { Chemotherapy } \\
\text { recommended: after } \\
\text { Oncotype }\end{array}$ & 43 & 30.3 & 3 & 2.1 & 19 & 13.4 & 21 & 14.8 & \\
\hline
\end{tabular}

those not receiving chemotherapy (GBP 20418 (13053) versus GBP 9987 (7577); $P<0.00$; Table 2). This was primarily driven by the costs of chemotherapy drugs, although patients receiving chemotherapy also incurred significantly higher costs attributable to district nurse visits and hospital stays.

Decision impact results. Initially, 57 (40.14\%) of the 142 patients were recommended chemotherapy and hormone therapy. In 26 of these 57 patients $(45.61 \%)$, treatment was revised to hormone therapy alone after the RS was made available. The remaining 85 (59.86\%) patients were initially advised that hormone therapy alone would be sufficient, but, after review of the RS, 12 (14.12\%) of these were advised chemotherapy as well. Overall, the chemotherapy decision was changed after Oncotype DX testing in $38(26.76 \%)$ of patients representing an overall reduction in chemotherapy recommendation in 14 of 142 patients (9.9\%). In the low RS group, 26 of 79 patients were initially recommended for chemotherapy, of which 23 were then recommended against $(-88.4 \%)$. In the intermediate RS group, 16 of 39 patients were initially advised chemotherapy, which was increased to 19 on receipt of the results $(+18.6 \%)$. In the high RS group, 15 of 24 patients were initially recommended chemotherapy, which was increased to $21(+40 \%)$. The final chemotherapy recommendations were 3 of $79(3.7 \%)$ in the low RS group, 19 of $39(48.7 \%)$ in the intermediate RS group and 21 of $24(87.5 \%)$ in the high RS group. The results are summarised in Table 4. 
Decision conflict results. Of the 45 patients who completed initial DCS questionnaire, 44 completed all 16 items and 1 patient missed 9 items. This left 44 patients in whom a total score could be calculated. In all, 41 patients completed the subsequent DCS questionnaire, of whom 40 completed all 16 items and 1 missed 9 items, leaving 40 patients with fully completed questionnaires. There were 39 patients with DCS total scores from both initial and subsequent questionnaires all of which had all 16 items completed for both. The results are summarised in Table 5. Statistically significant decreases from initial to subsequent DCS scores were noted in the total score, informed and uncertainty subscores and non-significant changes in the values clarity, support and effective decision subscores.

Cost-effectiveness results. The use of Oncotype DX testing was projected to increase mean life expectancy by 0.16 years and quality-adjusted life expectancy by 0.14 QALYs compared with current clinical practice in N0 and pN1mi early-stage breast cancer. The benefits in terms of improved quality-adjusted life expectancy were driven by optimised allocation of adjuvant chemotherapy in terms of chemotherapy sparing in patients unlikely to derive clinical benefit and ensuring patients likely to benefit received chemotherapy. In terms of cost, the mean total direct cost in the Oncotype DX group was GBP 12735 compared with GBP 11847 in the current clinical practice group (difference

\begin{tabular}{|c|c|c|c|}
\hline Decision & $\begin{array}{l}\text { Patient } \\
\text { number }\end{array}$ & $\begin{array}{c}\% \text { Of } \\
\text { patients }\end{array}$ & $\begin{array}{l}\text { \% Changed following } \\
\text { Oncotype DX testing }\end{array}$ \\
\hline $\begin{array}{l}\text { HT only } \\
\text { unchanged }\end{array}$ & 73 & 51.41 & - \\
\hline $\begin{array}{l}\text { HT changed to } \\
\mathrm{HT}+\mathrm{CT}\end{array}$ & 12 & 8.45 & 14.12 \\
\hline $\begin{array}{l}\mathrm{CT}+\mathrm{HT} \\
\text { unchanged }\end{array}$ & 31 & 21.83 & - \\
\hline $\begin{array}{l}\mathrm{CT}+\mathrm{HT} \\
\text { changed to HT } \\
\text { only }\end{array}$ & 26 & 18.31 & 45.61 \\
\hline
\end{tabular}

\begin{tabular}{|l|c|c|c|c|}
\hline \multicolumn{1}{|c|}{ Table 5. Summary of decision conflict results } \\
\hline & $\begin{array}{c}\text { Initial mean } \\
(95 \% \mathrm{Cl})\end{array}$ & $\begin{array}{c}\text { Review } \\
\text { mean } \\
(95 \% \mathrm{Cl})\end{array}$ & $\begin{array}{c}\text { Mean } \\
\text { change }\end{array}$ & P-value \\
\hline $\begin{array}{l}\text { Informed } \\
\text { subscore }\end{array}$ & $14.5(10.5,18.6)$ & $9.8(6.0,13.6)$ & -4.7 & 0.024 \\
\hline $\begin{array}{l}\text { Values clarity } \\
\text { subscore }\end{array}$ & $15.6(11.6,19.6)$ & $12.2(8.1,16.3)$ & -3.4 & 0.125 \\
\hline $\begin{array}{l}\text { Support } \\
\text { subscore }\end{array}$ & $10.7(7.0,14.3)$ & $9.2(5.3,13.0)$ & -1.5 & 0.484 \\
\hline $\begin{array}{l}\text { Uncertainty } \\
\text { subscore }\end{array}$ & $22.0(14.6,29.4)$ & $13.0(8.0,18.0)$ & -9.0 & 0.004 \\
\hline $\begin{array}{l}\text { Effective } \\
\text { decision } \\
\text { subscore }\end{array}$ & $12.0(8.1,15.9)$ & $9.5(5.2,13.7)$ & -2.6 & 0.176 \\
\hline Total score & $14.8(10.9,18.7)$ & $10.7(6.9,14.4)$ & -4.1 & 0.030 \\
\hline Abbreviation: Cl=confidence interval. & & & \\
\hline
\end{tabular}

GBP 888). Assessment of cost-effectiveness showed that the use of Oncotype DX was associated with an incremental cost-effectiveness ratio (ICER) of GBP 6232 per QALY gained and GBP 5633 per life year gained in comparison with current clinical practice (Table 6).

The results of one-way sensitivity analyses identified the key drivers of outcomes as patient age, the cost of Oncotype DX testing and changes in chemotherapy recommendations for patients deemed to be at low risk of distant recurrence. The benefit of chemotherapy in the intermediate risk group is unknown, but, even if it is assumed to be zero, univariate analysis around this parameter shows a change in ICER from base case of $+£ 551$ per QALY to $£ 6783$ (Figure 2).

The single biggest driver of outcomes was patient age; decreasing the mean age to 45 years (versus 60.55 years in the base case) led to an ICER of GBP 4628 per QALY gained, whereas increasing patient age to 75 years led to an ICER of GBP 16537 per QALY gained. The results were largely robust to changes in input assumptions regarding changes in chemotherapy use in patients with high RS score, the cost of managing adverse events and the disutility associated with chemotherapy. The results of PSA showed that there was a $99.6 \%$ probability that the Oncotype DX assay would be considered cost-effective in comparison with current clinical practice in the UK setting, assuming a willingness to pay threshold of GBP 20000 per QALY gained.

A comparison of costs and cost differences between patients receiving and not receiving chemotherapy as calculated using the patients' diary of events, notes and prescriptions and the results summarised in Table 7 showed that the total economic cost to the NHS of testing this cohort of 142 patients was $£ 220326$.

\section{DISCUSSION}

The use of adjuvant chemotherapy following complete surgical excision has proven survival advantages particularly for patients with a poor prognosis where the potential advantage is greatest. However, identifying individual patients who can derive benefit from chemotherapy is challenging but assuming greater importance not only for economic reasons but also because of the increasing concern about overtreatment of women in the national screening programme. Quantitative analysis of gene expression in tumours has the potential to identify those responsive to chemotherapy and as such provides an excellent example of personalised medicine. The Oncotype DX assay looks at the expression of a panel of 16 tumour-related genes (and 5 reference genes) and can predict chemotherapy benefit rather than simply prognosis.

The trial was intended to include all eligible women sequentially, although at review after the first third of the cases were

\begin{tabular}{|c|c|c|c|}
\hline & $\begin{array}{l}\text { Current } \\
\text { clinical } \\
\text { practice }\end{array}$ & $\begin{array}{c}\text { With } \\
\text { Oncotype DX } \\
\text { testing }\end{array}$ & Difference \\
\hline $\begin{array}{l}\text { Life expectancy } \\
\text { (years) }\end{array}$ & 14.73 & 14.89 & 0.16 \\
\hline $\begin{array}{l}\text { Quality-adjusted life } \\
\text { expectancy (QALYs) }\end{array}$ & 11.39 & 11.54 & 0.14 \\
\hline Cost (GBP) & 11847 & 12735 & 888 \\
\hline $\begin{array}{l}\text { ICER (GBP per QALY } \\
\text { gained) }\end{array}$ & & 6232 & \\
\hline \multicolumn{4}{|c|}{$\begin{array}{l}\text { Abbreviations: ICER }=\text { incremental cost-effectiveness ratio; } Q A L Y=\text { quality-adjusted life } \\
\text { year. Costs are presented in } 2010 \text { Pounds Sterling. }\end{array}$} \\
\hline
\end{tabular}




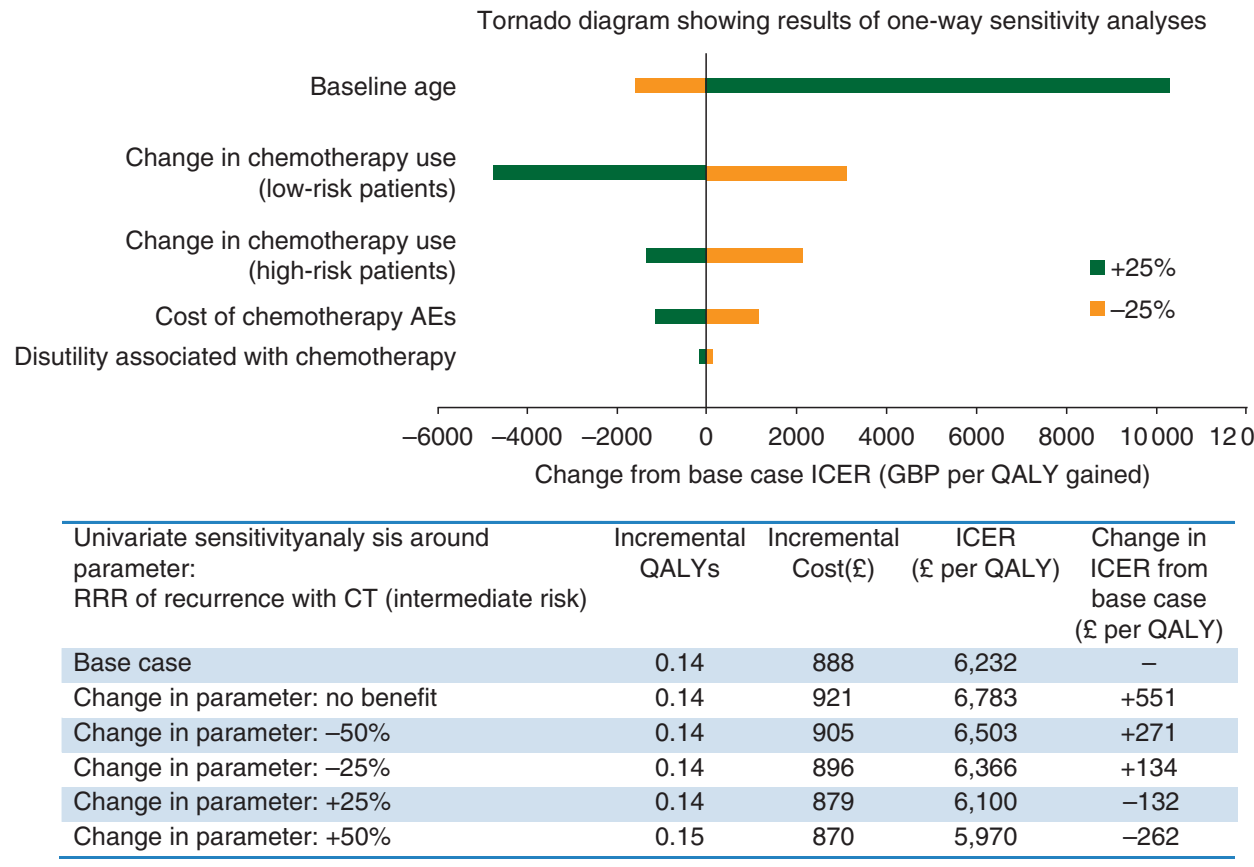

Figure 2. Tornado diagram showing results of one-way sensitivity analyses.

\begin{tabular}{|c|c|}
\hline Outcome & Value \\
\hline $\mathrm{A}=$ changed not to receive chemotherapy & 26 \\
\hline $\mathrm{B}=$ changed to receive chemotherapy & 12 \\
\hline $\begin{array}{l}\mathrm{C}=\text { incremental health-care cost of patients receiving } \\
\text { chemotherapy }\end{array}$ & $£ 10431$ \\
\hline $\mathrm{D}=$ cost commercially of Oncotype DX test & $£ 2580$ \\
\hline $\mathrm{T}=$ total number of patients tested & 142 \\
\hline Estimated economic impact to the National Health Service & $£ 220326$ \\
\hline
\end{tabular}

recruited, some case selection was evident. After clarification with the oncologists subsequent recruitment followed the protocol much more closely. We interpret the results as broadly reflecting the effect of unselected testing in this group.

This decision impact study performed in 142 patients with early-stage ER + node-negative breast cancer shows that use of the Oncotype DX assay has a notable impact on chemotherapy prescribing, resulting in changes in treatment recommendations in $26.8 \%(n=38)$. In particular, $45.6 \%$ of patients initially recommended both chemotherapy and endocrine therapy had their treatment recommendation changed to endocrine therapy alone when their tumour returned a low or low-intermediate RS. This group of patients was not only spared the considerable inconvenience, risk and personal economic impact of chemotherapy but also the unknown long-term effects.

Of the 85 patients initially recommended hormone therapy alone, 12 (14.1\%) were advised to receive chemotherapy in addition following Oncotype DX testing, which returned a high intermediate or high recurrence score. Although these patients were fewer in number, they are, arguably, the most important group to identify because they are most likely to benefit from testing. Although we thought these patients might be the most difficult to manage, they were, in the event, the most grateful, realising that they would otherwise have been deprived of treatment which would reduce their risk of relapse.
The UK figure of $27 \%$ change in treatment recommendations in node-negative ER + women compares with similar impact studies carried out in Europe with Germany showing a 33\% change (Eiermann et al, 2012), Spain 32\% (Albanell et al, 2012a), France $34 \%$ (Gligorov et al, 2012) and the European meta-analysis of those studies 31.9\% (Albanell et al, 2012b). Oncotype DX testing in one centralised laboratory is likely to contribute to this consistency.

Although only about one-third of the patients were asked to complete questionnaires, decision conflict was also assessed in the present analysis, the results of which suggest that the use of Oncotype DX gives patients increased confidence in their treatment decision. These results represent a $28 \%$ reduction in the DCS total score, which concurs with the analysis of Lo et al (2010), in which a $30 \%$ reduction was observed.

A number of cost-effectiveness analyses of the Oncotype DX assay for other settings, including the Unites States, Canada, Japan, Israel and Germany, have been published (Hornberger et al, 2005; Lyman et al, 2007; Klang et al, 2010; Kondo et al, 2011; Blohmer et al, 2012; Lamond et al, 2012). These previous analyses have shown that use of the Oncotype DX assay is cost-effective (or costsaving in the United States and Germany) from the perspective of a third-party payer, with clinical benefits being primarily driven by the sparing of chemotherapy. The results of the current analysis concur and suggest that the Oncotype DX assay can be considered to be cost-effective in the UK setting in comparison with current clinical practice.

The greatest change in the ICER value occurred when mean patient age was increased to 75 years. This led to an ICER of GBP 16537 per QALY gained for Oncotype DX versus current clinical practice. However, even in this scenario, it is likely that Oncotype DX could be considered cost-effective in comparison with current clinical practice. The substantial increase in ICER with increasing baseline patient age is attributable to competing mortality.

The budget impact calculation is expected to be an over estimate of the actual impact of the introduction of Oncotype DX testing owing to a number of factors. First, the present study enrolled near consecutive patients, a number of whom would not be expected to receive the test were it introduced in the NHS. Indeed, in the United States where the test is broadly reimbursed since 2005, a recent review of patterns of care reports that in real-life clinical 
practice, physicians tend to select patients to whom they offer the test and not all potentially eligible patients receive it (Winer and Sparano, 2011). Second, HER2-positive patients (four cases, 2.8\%) were included in this study, but experience shows that testing this group is unnecessary as HER2 positivity is a reliable predictor of high recurrence score and, in any case, few oncologists would deprive these patients of the benefit of chemotherapy. Therefore, the total acquisition costs of the test would be reduced, lessening the impact on health-care spending.

Reviewing the patient characteristics in this cohort shows that women with low grade, ER and PR strongly positive tumours, or high grade, ER or PR less than 7/8 positive, are least likely to have their adjuvant therapy decisions changed by the Oncotype DX assay (Table 3 ). If testing in this series had been restricted, first, to women scheduled for chemotherapy and, second, to those not recommended chemotherapy with grade 2 or 3 tumours and PR by IHC $6 / 8$ or less, then $92 \%$ or the changes would have been captured and $41 \%$ of the cost of testing spared. Furthermore, the budget impact analysis only captures short-term costs, such as the costs of chemotherapy and the acquisition cost of the test, whereas the cost-effectiveness analysis examines the long-term impact of the test. Consequently, budget impact is driven by chemotherapy cost savings when patients change adjuvant chemotherapy recommendation, whereas the cost-effectiveness results also incorporate recurrences avoided, the costs of which are not captured in the budget impact analysis. As the Oncotype DX assay identifies patients who would be undertreated through not receiving chemotherapy under current practice, the costs of recurrence would be expected to be lower in the analysis where the test was used. For these several reasons, we conclude that the presented impact on health-care spending is an over estimate.

The current analysis was performed from a third-party payer perspective, and as such only takes into account the direct economic costs to the NHS. It does not take into account the impact of indirect costs associated with travel, lost work time and treatment costs associated with long-term side-effects. The current analysis does not capture long-term productivity; one of the strongest predictors for not returning to work after treatment for breast cancer is receipt of chemotherapy (Johnsson et al, 2009). Breast cancer and breast cancer treatment also have a notable impact on personal life, family life and a wider impact in terms of loss to employers and prolonged sickness benefits from the state. These have not been taken into account in this study.

In conclusion, decision impact analysis has shown that the use of the Oncotype DX assay has a considerable influence on chemotherapy treatment recommendations in patients with ER + early-stage breast cancer. It is associated with substantial chemotherapy sparing in patients likely to derive little or no benefit from treatment and assists in the identification of patients currently considered at low risk who will in fact benefit from chemotherapy. Cost-effectiveness evaluation shows that the use of the Oncotype DX assay is associated with improved life expectancy and quality-adjusted life expectancy in comparison with current clinical practice and is likely to be costeffective in the UK using current thresholds.

\section{ACKNOWLEDGEMENTS}

This study was supported by funding from Genomic Health International.

\section{REFERENCES}

Aebi S, Davidson T, Gruber G, Castiglione M (2010) Primary breast cancer: ESMO Clinical Practice Guidelines for diagnosis, treatment and follow-up. Ann Oncol 21(Suppl 5): v9-v14.
Albain KS, Barlow WE, Shak S, Gabriel N, Hortobagyi GN, Livingston Robert B, Yeh I-Tien, Ravdin Peter, Bugarini Roberto, Baehner Frederick L, Davidson Nancy E, Sledge George W, Winer Eric P, Hudis Clifford, Ingle James N, Perez Edith A, Pritchard Kathleen I, Shepherd Lois, Gralow Julie R, Yoshizawa Carl, Craig Allred D, Kent Osborne C, Hayes Daniel F (2010) Prognostic and predictive value of the 21-gene recurrence score assay in a randomized trial of chemotherapy for postmenopausal, node-positive, estrogen receptor-positive breast cancer on chemotherapy: a retrospective analysis of a randomised trial. Lancet Oncol 11(1): 55-65.

Albanell J, Colomer R, Ruiz Borrego M, Alba E, García-Saenz JA, Corominas JM, Burgues O, Furio V, Rojo A, Palacios J, Bermejo B, Martínez-García M, Limon ML, Muñoz AS, Martín M, Tusquets I, Rojo F, Colomer R, Faull I, Lluch A (2012a) Prospective transGEICAM study of the 21-gene Recurrence Score assay and traditional clinicopathological factors on adjuvant clinical decision making in women with estrogen receptor-positive $(\mathrm{ER}+)$ node-negative breast cancer. Ann Oncol 23: 625-631.

Albanell J, Gligorov J, Holt S, Blohmer J, Eiermann W, Svedmann C (2012b) Meta-Analysis of Prospective European Studies Assessing the Impact of Using the 21-gene Recurrence Score Assay on Clinical Decision Making in Women with ER +, HER2- Early Stage Breast Cancer. Poster 252PD, European Society of Medical Oncology: Vienna.

Blohmer JU, Rezai M, Kümmel S (2012) Using the 21-gene assay to guide adjuvant chemotherapy decision-making in early-stage breast cancer: a cost-effectiveness evaluation in the German setting. J Med Econ 16: $30-40$.

BNF 61: Joint Formulary Committee (2011) British National Formulary 61st Edition. Pharmaceutical Press: London.

Conner-Spady BL, Cumming C, Nabholtz JM, Jacobs P, Stewart D (2005) A longitudinal prospective study of health-related quality of life in breast cancer patients following high-dose chemotherapy with autologous blood stem cell transplantation. Bone Marrow Transplant 36: 251-259.

Eiermann W, Rezai M, Kümmel S, Kühn T, Warm M, Friedrichs K, Schneeweiss A, Markmann S, Eggemann H, Hilfrich J, Jackisch C, Witzel I, Eidtmann H, Bachinger A, Hell S, Blohmer J (2013) The 21-gene recurrence score assay impacts adjuvant therapy recommendations for ER-positive, node-negative and node-positive early breast cancer resulting in a risk-adapted change in chemotherapy use. Ann Oncol 24: 618-624.

Harris L, Fritsche H, Mennel R, Norton L, Ravdin P, Taube S, Somerfield MR, Hayes DF, Bast Jr RC (2007) American Society of Clinical Oncology 2007 update of recommendations for the use of tumor markers in breast cancer. $J$ Clin Oncol 25: 5287-5312.

Genomic Health Ltd (2013 price list). http://www.genomichealth.com/en-US/ OncotypeDX.aspx\#.UYoz2kpia3g (Accessed 8 May 2013).

Gligorov J, Pivot XB, Naman HL, Jacot W, Spaeth D, Misset JL, Largillier R, Sautiere JL, de Roquancourt A, Pomel C, Rouanet P, Rouzier R, PenaultLlorca FM (2012) Prospective study of the impact of using the 21-gene recurrence score assey on clinical decision making in women with estrogen-receptor positive, HER2 negative, early stage breast cancer in France. J Clin Oncol 30: 24s Poster 568.

Goldhirsch A, Wood WC, Coates AS, Gelber RD, Thürlimann B, Senn HJ (2011) Strategies for subtypes - dealing with the diversity of breast cancer: highlight of the St Gallen international expert concensus on the primary therapy of early breast cancer 2011. Ann Oncol 22(8): $1736-1747$.

Hind D, Ward S, De Nigris E, Simpson E, Carroll C, Wyld L (2007) Hormonal therapies for early breast cancer: systematic review and economic evaluation. Health Technol Assess 11: 1-134.

Hornberger J, Cosler LE, Lyman GH (2005) Economic analysis of targeting chemotherapy using a 21-gene RT-PCR assay in lymph-node-negative, estrogen-receptor-positive, early-stage breast cancer. Am J Manag Care 11: 313-324.

Holt SDH, Pudney D, Rolles M, Moe M, Brinkworth E, Whelan S, Khawaja S, Pitcher S, Sharaiha Y, Bertelli G (2011) Results from a Prospective Clinical Study on the Impact of Oncotype DX on Adjuvant Treatment Decision and Risk Classification by Nottingham Prognostic Index(NPI) and Adjuvant! Online. Poster Presentation at the 12th St Gallen International Breast Cancer Conference: St Gallen, Switzerland.

Johnsson A, Fornander T, Rutqvist L, Vaez M, Alexanderson K, Olsson M (2009) Predictors of return to work ten months after primary breast cancer surgery. Acta Ocologica 48: 93-98.

Klang SH, Hammerman A, Liebermann N, Efrat N, Doberne J, Hornberger J (2010) Economic implications of 21-gene breast cancer risk assay from the 
perspective of an Israeli-managed health-care organization. Value Health 13(4): 381-387.

Kondo M, Hoshi SL, Yamanaka T, Ishiguro H, Toi M (2011) Economic evaluation of the 21-gene signature (Oncotype DX) in lymph nodenegative/positive, hormone receptor-positive early-stage breast cancer based on Japanese validation study (JBCRG-TR03). Breast Cancer Res Treat 127: 739-749.

Lamond NW, Skedgel C, Rayson D, Lethbridge L, Younis T (2012) Cost-utility of the 21-gene recurrence score assay in node-negative and node-positive breast cancer. Breast Cancer Res Treat 133: 1115-1123.

Lo S, Norton J, Mumby P, Rychlik K, Smerage J, Kash J, Chew HK, Gaynor ER, Hayes DF, Epstein A, Albain KS (2010) Prospective multi-center study of the impact of the 21-gene Recurrence Score assay on medical oncologist and patient adjuvant breast cancer treatment selection. J Clin Oncol 28: $1671-1676$.

Lyman GH, Cosler LE, Kuderer NM, Hornberger J (2007) Impact of a 21-gene RT-PCR assay on treatment decisions in early-stage breast cancer: an economic analysis based on prognostic and predictive validation studies. Cancer 109: 1011-1018.

Milne RJ, Heaton-Brown KH, Hansen P, Thomas D, Harvey V, Cubitt A (2006) Quality-of-life valuations of advanced breast cancer by New Zealand women. Pharmacoeconomics 24: 281-292.

Office for National Statistics (2010) 2007-2009 Interim Life Tables, Accessed at http://www.ons.gov.uk/ons/rel/lifetables/interim-life-tables/interim-lifetables/index.html (Accessed on 8 May 2013).
NCCN Clinical Practice Guidelines in Oncology ${ }^{\mathrm{TM}}$ Breast Cancer (Version 1 (2011). http://www.wales.nhs.uk/sites3/home.cfm?OrgID=242 (Accessed 8 May 2013).

NICE costing template 112. http://guidance.nice.org.uk/TA112/Costing Report/xls/English (Accessed 8 May 2013).

Paik S, Tang G, Shak S, Kim C, Baker J, Kim W, Cronin M, Baehner FL, Watson D, Bryant J, Costantino JP, Geyer Jr CE, Wickerham DL, Wolmark N (2006) Gene expression and benefit of chemotherapy in women with node-negative, estrogen receptor-positive breast cancer. J Clin Oncol 24: 3726-3734.

Peasgood T, Ward SE, Brazier J (2010) Health-state utility values in breast cancer. Expert Rev Pharmacoecon Outcomes Res 10(5): 553-566.

Simes RJ, Coates AS (2001) Patient preferences for adjuvant chemotherapy of early breast cancer: how much benefit is needed? J Natl Cancer Inst Monogr 30: 146-152.

Thomas RJ, Williams M, Marshall C, Glen J, Callam M (2009) The total hospital and community UK costs of managing patients with relapsed breast cancer. Br J Cancer 100(4): 598-600.

Winer EP, Sparano JA (2011) Patterns of care, Breast cancer edition, issue I. http://www.researchtopractice.com/browse-by-tumor-types/patterns-carebreast-cancer-edition?tumor-type $=1$ \&year $=2011$.

(c) (i) (2) This work is licensed under the Creative Commons c) Attribution-NonCommercial-Share Alike 3.0 Unported License. To view a copy of this license, visit http://creativecommons. org/licenses/by-nc-sa/3.0/ 